\title{
Evaluation of liver transplant recipients underwent incidental appendectomies
}

\author{
(1) Cemalettin Koc, (1) Sami Akbulut, (으 Baris Sarici, (1) Sezai Yilmaz \\ Department of Surgery and Liver Transplant Institute, Inonu University Faculty of Medicine, Malatya, Turkey
}

\begin{abstract}
OBJECTIVE: To assess the clinicopathological features of liver transplant recipients underwent incidental appendectomies. METHODS: Between September 2002 and July 2019, 2500 patients underwent liver transplantation at our Liver Transplant Institute, including 38 (24 males, 14 females) who also underwent incidental appendectomies. Incidental appendectomies were performed on 24 patients during recipient hepatectomies and on 14 during relaparotomies due to various surgical conditions. The following patient parameters were retrospectively evaluated: age, sex, underlying liver disease, liver transplant type, appendectomy indication, appendix length $(\mathrm{mm})$ and diameter $(\mathrm{mm})$, presence of appendicitis, and histopathological findings.

RESULTS: The 38 patients who underwent incidental appendectomies had a mean age of $18.3 \pm 21.7$ (range: 1-66) years and median appendix lengths and diameters of 55 (range: 19-90) mm and 6 (range: 4-20) mm, respectively. Histopathologically, the appendectomy specimens were classified as follows: vermiform appendix $(n=16)$, lymphoid hyperplasia ( $n=13)$, acute appendicitis $(n=3)$, fibrous obliteration $(n=3)$, perforated appendicitis $(n=1)$, mucinous cystadenoma $(n=1)$, and appendiceal serosa invasion by sigmoid adenocarcinoma $(n=1)$. There were no postoperative complications, including wound infections, abscesses, or leakage from the appendiceal stumps, related to the incidental appendectomies.
\end{abstract}

CONCLUSION: This study demonstrated that incidental appendectomies can be successfully performed in immunosuppressed patients. However, additional studies are required to confirm these results.

Keywords: Appendicitis; incidental appendectomy; liver transplantation, recipients.

Cite this article as: Koc C, Akbulut S, Sarici B, Yilmaz S. Evaluation of liver transplant recipients underwent incidental appendectomies. North Clin Istanb 2020;7(4):386-390.

A cute appendicitis is the most frequent cause of emergency department admissions due to suddenonset abdominal pain [1-4]. Further, lymphoid hyperplasia and appendiceal lumen obstruction by fecaliths are the two most frequent etiologies of acute appendicitis in children and adults, respectively $[3,4]$. In males, the lifetime risk of acute appendicitis is $8.6 \%$; in females, the risk is $6.9 \%$ [5-8]. However, epidemiology studies have shown that the risk of undergoing an appendectomy, at any stage of life, is $12-23 \%$ [7-9]. The difference between the risks of appendicitis and appendectomy re- sults from appendectomies being performed for varied reasons and the removal of a vermiform appendix during abdominal surgery for an unrelated cause, which is defined as an incidental appendectomy $[10,11]$. Since the initial definition of incidental appendectomy was proposed, determining when patients undergo incidental appendectomies has remained controversial. The present study analyzed specimen histopathologic data and the demographic and clinical characteristics of patients who underwent incidental appendectomies during liver transplantation (LT) surgeries. 


\section{MATERIALS AND METHODS}

\section{Study Design}

Between September 2002 and July 2019, 2500 patients underwent LT at our Liver Transplantation Institute, including 38 (24 males, 14 females) who also underwent incidental appendectomies during LT or during re-laparotomy in the early postoperative period. The following criteria, recognized by international associations, were used to determine the appropriateness of incidental appendectomy: (i) increased risk of appendicitis after major abdominal surgery, such as LT; (ii) the risk of complications and the duration of surgery may increase when the appendectomy is performed in patients with histories of major abdominal surgeries; (iii) the lateral end of the J incision used for recipient hepatectomy is very close to the ileocecal region and, therefore, increases the risk of manipulation of the vermiform appendix during abdominal wall retraction; (iv) palpable fecaliths within the vermiform appendix; and (v) intraoperative findings suggestive of acute appendicitis, including a vermiform appendix that is increased in size, demonstrating wall edema or hyperemia, and is erect $[8,9]$. Experienced gastrointestinal surgeons made the decisions to perform incidental appendectomies. The appendectomy procedure was performed as previously described. Since patients who underwent incidental appendectomies were also going to use immunosuppressive drugs during the postoperative period, each appendix stump was ligated, and transposition sutures were made, using polypropylene sutures, to avoid stump failures. The following patient demographic and clinicopathologic characteristics were evaluated as part of the study: age (years), sex (male, female), appendix length $(\mathrm{mm})$, appendix diameter $(\mathrm{mm})$, presence of appendicitis, and unusual histopathological findings.

\section{Statistical Analysis}

Statistical Package for Social Sciences Software for Windows version 25.0 (SPSS Inc, Chicago, IL, USA) was used to perform all statistical analyses. Quantitative variables are expressed as means \pm standard deviations or as medians and ranges; qualitative variables are reported as numbers and percentages. This study was conducted in accordance with the principles stated in the Declaration of Helsinki.

\section{Immunosuppression Protocol After Liver}

Aransplantation

Initially, methylprednisolone was administered immediately after the completion of the hepatic artery anastomo- sis during graft implantation. Postoperatively, steroids were started $(100 \mathrm{mg} /$ day $)$, tapered to $0.25 \mathrm{mg} / \mathrm{kg} /$ day, and discontinued 3-6 months after surgery, except for patients with autoimmune diseases, such as primary sclerosing cholangitis, primary biliary cholangitis, and autoimmune hepatitis. In most cases, tacrolimus was the first choice for immunosuppressive therapy, except in patients with renal dysfunction or hepatorenal syndrome; mycophenolate mofetil and tacrolimus were usually initiated on postoperative day 3. In patients with impaired or deteriorated renal function, tacrolimus was stopped or tapered and everolimus was added until renal function improved [12].

\section{RESULTS}

Incidental appendectomies were performed in $38 \mathrm{pa}-$ tients, with a mean age of $18.3 \pm 21.7$ (range: $1-66$ ) years; 32 patients underwent living donor liver transplantation (LDLT) and 6 patients underwent deceased donor liver transplantation (DDLT). One patient who underwent LDLT underwent re-transplantation from a deceased donor. The LT indications were cryptogenic cirrhosis $(n=9)$, biliary atresia $(n=5)$, hepatitis $B$ virus infection $(\mathrm{n}=5)$, hepatitis A virus-associated acute liver failure $(n=3)$, neonatal hepatitis $(n=3)$, Budd-Chiari Syndrome $(n=2)$, hepatitis $C$ virus infection $(n=2)$, hepatocellular carcinoma $(\mathrm{n}=2)$, alpha 1 antitrypsin deficiency $(n=1)$, alcoholic cirrhosis $(n=1)$, autoimmune hepatitis $(n=1)$, hepatoblastoma $(n=1)$, primary hepatic neuroendocrine carcinoma $(n=1)$, progressive familial intrahepatic cholestasis $(\mathrm{n}=1)$, and polycystic liver disease $(n=1)$. Table 1 summarizes the demographic, clinical, and histopathologic characteristics of the patients.

For 24 patients, incidental appendectomies were performed during LT, whereas 14 patients underwent incidental appendectomy during re-laparotomy in the early post-transplant period. The indications for re-laparotomy were gastrointestinal perforation $(n=5)$, mechanical bowel obstruction ( $n=4)$, perforated Meckel's diverticulum ( $\mathrm{n}=1)$, artificial vascular graft migration to the hollow viscus organ $(n=1)$, colonic ischemia $(n=1)$, pelvic mass due to sigmoid colon tumor $(\mathrm{n}=1)$, and intra-abdominal bleeding $(n=1)$. For two patients, the vermiform appendixes were included among the retrieved specimens due to distal ileal resections.

The histopathological findings for the incidental appendectomy specimens were normal appendix vermiformis $(n=16)$, lymphoid hyperplasia $(n=13)$, acute appendicitis $(n=3)$, fibrous obliteration $(n=3)$, perforated 
TABLE 1. Demographic, clinical, and histopathological features of 38 liver transplant patients who underwent incidental appendectomies

\begin{tabular}{|c|c|c|c|}
\hline Patients' features & Results (\%) & Patients' features & Results (\%) \\
\hline Gender & & $\mathrm{HCC}$ & $2(5.3)$ \\
\hline Male & $24(63.2)$ & Alpha 1 antitrypsin deficiency & $1(2.6)$ \\
\hline Female & $14(36.8)$ & Autoimmune hepatitis & $1(2.6)$ \\
\hline Age & & Alcoholic cirrhosis & $1(2.6)$ \\
\hline Mean \pm SD & $18.3 \pm 21.7$ & Hepatoblastoma & $1(2.6)$ \\
\hline Median (Min.-Max.) & $6(1-66)$ & Neuroendocrine carcinoma & $1(2.6)$ \\
\hline MELD Score & & PFIC & $1(2.6)$ \\
\hline Mean \pm SD & $21.5 \pm 8.5$ & Polycystic liver disease & $1(2.6)$ \\
\hline Median (Min.-Max.) & $22(10-38)$ & Length of the appendix & \\
\hline PELD Score & & Mean \pm SD & $53.5 \pm 14.4$ \\
\hline Mean \pm SD & $22.6 \pm 9.4$ & Median (Min.-Max.) & $55(19-90)$ \\
\hline Median (Min.-Max.) & $23(6-38.8)$ & Diameter of the Appendix & \\
\hline LT Type & $32(842)$ & Mean \pm SD & $6.4 \pm 2.85$ \\
\hline $\begin{array}{l}\text { LDLT } \\
\text { DDLT }\end{array}$ & $\begin{array}{c}32(84.2) \\
6(15.8)\end{array}$ & Median (Min.-Max.) & $6(4-20)$ \\
\hline Indication for LT & (1.0) & Histopathological features & \\
\hline Cryptogenic cirrhosis & $9(23.7)$ & Appendix vermiformis & $16(42.1)$ \\
\hline HBV & $5(13.1)$ & Lymphoid hyperplasia & $13(34.2)$ \\
\hline Biliary atresia & $5(13.1)$ & Acute appendicitis & $3(7.9)$ \\
\hline HAV associated acute liver failure & $3(7.9)$ & Perforated appendicitis & $1(2.6)$ \\
\hline Neonatal hepatitis & $3(7.9)$ & Fibrous obliteration & $3(7.9)$ \\
\hline Budd-Chiari Syndrome & $2(5.3)$ & Mucinous cystadenoma & $1(2.6)$ \\
\hline $\mathrm{HCV}$ & $2(5.3)$ & Serosal tumor invasion & $1(2.6)$ \\
\hline
\end{tabular}

SD: Standard deviation; Min.: Minimum; Max.: Maximum; MELD: Model for end-stage liver disease; PELD: Pediatric end-stage liver disease; LT: liver transplantation; LDLT: Living donor liver transplantation; DDLT: Deceased donor liver transplantation; HBV: Hepatitis B virus; HAV: Hepatitis A virus; HCV: Hepatitis C virus; HCC: Hepatocellular carcinoma; PFIC: Progressive familial intrahepatic cholestasis.

appendicitis $(\mathrm{n}=1)$, mucinous cystadenoma $(\mathrm{n}=1)$, and appendiceal serosa invasion due to sigmoid adenocarcinoma $(n=1)$. Six of the 38 patients who underwent incidental appendectomies developed biliary or venous complications related to disrupted venous drainage during the postoperative period; all were successfully treated using interventional radiological procedures or endoscopic retrograde cholangiopancreatography. None of the patients suffered incidental appendectomy-related complications, such as surgical site infections, right lower quadrant/pelvic cavity intra-abdominal abscesses, or stump failures.

\section{DISCUSSION}

We aimed to assess the clinicopathological features of liver transplant recipients who underwent an incidental appendectomy. We observed that incidental appendectomy can be performed successfully even in immunosuppressed patients.

Appendectomies are classified into four groups, according to the procedure timing and indication: emergency (standard) appendectomy, elective (interval) appendectomy, prophylactic appendectomy, and incidental appendectomy $[3,9]$. An incidental appendectomy is defined as the resection of the vermiform appendix during an abdominopelvic surgery that was originally indicated for reasons other than appendiceal diseases. Since the term "incidental appendectomy" was originally defined by Kell in 1902, many controversies have arisen regarding which patients should undergo the procedure $[8,9$, 13]. Naturally, gynecologists, surgeons, and urologists publish the majority of studies describing incidental appendectomies. One of the important points concerning 
incidental appendectomies is the histopathologic findings of the resected surgical specimens. The most frequently reported pathologic findings of these specimens are normal appendix vermiformis (22.6-89.2\%), endometriosis $(0-37 \%)$, acute appendicitis $(0-9.2 \%)$, and various appendiceal tumors $(0-4.2 \%)$ [9].

Some of the controversial points regarding incidental appendectomy are its cost-efficacy and necessity. Proponents of the procedure emphasize that an incidental appendectomy is a simple procedure with a negligible complication rate that does not prolong anesthesia time. Furthermore, regardless of the appendicitis risk, they emphasize that during appendectomies for appendicitis, the complication risk and operative time both increase due to the formation of adhesions following major operations. They further recommend appendectomies during major abdominopelvic operations whenever feasible [2, 8]. Additionally, tumors can be found in the incidental appendectomy specimens, providing another reason for performing incidental appendectomies $[1,8,9]$. Conversely, opponents of the procedure emphasize the fact that the appendiceal lumen is continuous with the colonic lumen and, during the procedure, fecal contamination of the peritoneal cavity may complicate the operation, possibly resulting in infectious complications and morbidity $[1,2,11]$.

Despite the opposing views, a partial consensus has been obtained regarding the condition of the immune system during an incidental appendectomy. Literature reports generally suggest that an appendectomy should not be performed if a patient has undergone chemotherapy or radiotherapy, has Crohn's disease, is in an unstable condition, or if artificial vascular grafts have been used during the operation $[8,9]$. The present study was completed to explore this opinion. We reported performing 38 incidental appendectomies in patients with end-stage liver disease and preoperative immune dysfunction; each patient also underwent intensive, postoperative immunosuppressive therapy. Despite this, we did not encounter any appendectomy-related complications during the postoperative period. We used transfixation sutures in conjunction with appendiceal stump ligation to prevent stump failures, in all patients. We also inverted the appendiceal stump in all patients. Our results show the validity of the procedure.

One patient, who underwent an incidental appendectomy, developed a severe encapsulating peritonitis that was initially thought to be due to primary peritonitis re- lated to end-stage liver disease [14]. However, dissection of the abdominal cavity revealed a perforated appendix; following an appendectomy and adhesiolysis, a successful LT was performed.

In summary, this study showed that in a center with a high volume of immunosuppressed patients and gastrointestinal surgery experience, incidental appendectomies can be safely performed in these patients. However, this retrospective study involved only a single center and described a small number of patients, which are limiting factors. This study also showed that transfixation suture reinforcement, following appendiceal stump ligation, is a suitable approach for reducing complication rates in immunosuppressed patients, even in cases with normal-appearing vermiform appendixes. Finally, the entire abdominal cavity of patients who underwent abdominal surgery for any reason, such as LT, should be gently palpated and the findings recorded in the surgical report to avoid medical problems.

Conflict of Interest: No conflict of interest was declared by the authors.

Financial Disclosure: The authors declared that this study has received no financial support.

Authorship Contributions: Concept - SA, CK; Design - SA, CK; Supervision - SA, SY; Materials - CK, BS; Data collection and/or processing - BS, CK, SA; Analysis and/or interpretation - SA, SY; Writing - SA, CK; Critical review - SY, SA.

\section{REFERENCES}

1. de Lacerda Rodrigues Buzatti KC, da Silva RG, e Silva Rodrigues BD. Incidental and Prophylactic Appendectomy in Clinical Practice: A Review Article J Surg Transplant Sci 2017;5:1060.

2. Chen HK, Chu CC, Uen YH, Chen MJ, Ho CH. The Value of incidental appendectomy in Lower Abdominal Surgery: A Retrospective Study of Taiwan's National Health Insurance Research Database. Ann Emerg Surg 2017;2:1010.

3. Akbulut S, Tas M, Sogutcu N, Arikanoglu Z, Basbug M, Ulku A, et al. Unusual histopathological findings in appendectomy specimens: a retrospective analysis and literature review. World J Gastroenterol 2011;17:1961-70. [CrossRef]

4. Yilmaz M, Akbulut S, Kutluturk K, Sahin N, Arabaci E, Ara C, et al. Unusual histopathological findings in appendectomy specimens from patients with suspected acute appendicitis. World J Gastroenterol 2013;19:4015-22. [CrossRef]

5. Seetahal SA, Bolorunduro OB, Sookdeo TC, Oyetunji TA, Greene WR, Frederick W, et al. Negative appendectomy: a 10-year review of a nationally representative sample. Am J Surg 2011;201:433-7. [CrossRef]

6. Iamarino APM, Juliano Y, Rosa OM, Novo NF, Favaro ML, Ribeiro MAF Júnior. Risk factors associated with complications of acute appendicitis. Rev Col Bras Cir 2017;44:560-6. [CrossRef]

7. Baird DLH, Simillis C, Kontovounisios C, Rasheed S, Tekkis PP. 
Acute appendicitis. BMJ 2017;357:j1703. [CrossRef]

8. Akbulut S, Koc C, Kocaaslan H, Gonultas F, Samdanci E, Yologlu S, et al. Comparison of clinical and histopathological features of patients who underwent incidental or emergency appendectomy. World J Gastrointest Surg 2019;11:19-26. [CrossRef]

9. Akbulut S, Koc C, Sarici B, Ozcan M, Samdanci E, Yilmaz S. Histopathological features of incidental appendectomy specimens obtained from living liver donors. Turk J Gastroenterol 2020;31:257-63.

10. Romero RG, Glass JL, Russek KC, Franklin Jr ME. The role of incidental appendectomy in the setting of Cholecystectomy for symptomatic cholelithiasis in young women: A prospective comparative study. SAGES, 30 March-2 April 2011, San Antonio, TX, USA. Available at: https:// www.sages.org/meetings/annual-meeting/abstracts-archive/the-roleof-incidental-appendectomy-in-the-setting-of-cholecystectomy-f or-symptomatic-cholelithiasis-in-young-women-a-prospectivecomparative-study/. Accessed Apr 24, 2020.

11. Healy JM, Olgun LF, Hittelman AB, Ozgediz D, Caty MG. Pediatric incidental appendectomy: a systematic review. Pediatr Surg Int 2016;32:321-35. [CrossRef]

12. Barut B, Akbulut S, Kutluturk K, Koc C, Ozgor D, Aydin C, et al. Determination of risk factors affecting mortality in patients with gastrointestinal perforation after pediatric liver transplantation. Pediatr Transplant 2019;23:e13415. [CrossRef]

13. Kelly HA. Under what circumstances is it advisable to remove the vermiform appendix when the abdomen is opened for other reasons? JAMA 1902;39:1014-21. [CrossRef]

14. Akbulut S. Accurate definition and management of idiopathic sclerosing encapsulating peritonitis. World J Gastroenterol 2015;21:675-87. 